\title{
Effectiveness of Levofloxacin in Community Acquired Pneumonia in Adult Bangladeshi Population
}

\author{
Rokonuzzaman $\mathrm{SM}^{1}$, Ali $\mathrm{MH}^{2}$, Parvin $\mathrm{S}^{3}$, Prasad D ${ }^{4}$, Hossain $\mathrm{ME}^{5}$, Haque $\mathrm{R}^{6}$
}

\begin{abstract}
Community- acquired pneumonia (CAP) is a common condition with a significant mortality. Levofloxacin is recommended for the empiric management of CAP in inpatienst and outpatients. The present study conducted to find out the effectiveness of Levofloxacin in CAP among Bangladeshi Population. Total 50 Patients aged more than 18 years, diagnosed pneumonia based upon clinical features of respiratory tract infection and rediological changes, were included in this study. The study consists of four visits: first one for screening and enrollment. Second visit on day 2-4 during which patient on therapy, third visit 5-7 day after the last dose of the drug and fourth visit 28days after the last dose of the drug. The mean \# SD of age of the respondents was 34.3\# 19.1 years with a range of 18-100 years. Among the respondents $62.0 \%$ were male and $38.0 \%$ were female. Most of the respondents presented with fever (98.0\%) and cough (100.0\%) and chest pain was present in $66.0 \%$ cases. Ninety six percent respondents presented with productive cough and only $4.0 \%$ respondents with dry cough. Consolidation in left lower zone was the most common findings $(32.0 \%)$ followed by consolidation in right mild zone (30.0\%). Among the respondents $32.0 \%$ were treated with oral form and $68.0 \%$ were treated with injectable form of levofloxacin. About $92.0 \%$ were improved with the treatment. Levofloxacin monotherapy is well tolerated, cost-effective treatment for patients with CAP. Further large scale multi-centered study will help to strengthen this outcome.
\end{abstract}

Keywords: Community- acquired pneumonia (CAP); Levofloxacin.

1. Corresponding Author: Dr. S.M. Rokonuzzaman Associate Professor, Department of Medicine Uttara Adhunik Medical College Hospital, Uttara e- mail: 27mmcdrsmrz@gmail.com

2. Dr. Mohammad Hyder Ali

Professor and Head, Department of Medicine Uttara Adhunik Medical College

3. Dr. Soheli Parvin

Junior Consultant, Department of Radiology and Imaging Kuwait-Bangladesh Friendship Govt. Hospital

4. Dr. Deb Prasad Indoor Medical Officer, Department of Medicine Uttara Adhunik Medical College

5. Dr. Md. Enayet Hossain Associate Professor, Department of Medicine Sylhet MAG Osmani Medical College

6. Dr. Rashimul Haque Associate Professor, Department of Neuromedicine Uttara Adhunik Medical College

\section{Introduction}

Community-acquired pneumonia (CAP) is defined as signs and symptoms of an acute infection of the pulmonary parenchyma in a previously healthy patient who acquired the infection in the community ${ }^{1,2}$. The diagnosis of CAP is based primarily on clinical factors: a combination of signs and symptoms such as cough, fever, chills, sputum production, dyspnea, pleuritic pain, tachypnea, tachycardia, hypoxemia, features of consolidation on auscultation, and a new infiltrate on chest imaging $^{3}$. CAP is a common and potentially serious illness with considerable morbidity worldwide and places a large burden on medical and economic resources ${ }^{4-6}$. It is the leading cause of death in the world and remains a common and serious illness despite the availability of potent new anti- microbials and effective vaccines ${ }^{7,8}$. The mortality rate of pneumonia patients in out-patient settings is low, in the range of one to five per cent, but among patients who require admission to ICU it approaches $25 \%{ }^{9-12}$. Despite the availability of effective antimicrobial agents, CAP remains a significant cause of morbidity and mortality worldwide, especially among elderly individuals and individuals with coexisting disease $\mathrm{e}^{8,13}$. Today, physicians must choose an optimal therapeutic regimen that eradicates the respiratory infection effectively, minimizes the risk of development of resistance, and does not compromise the safety of the patient ${ }^{6}$. Treatment of patients with CAP is often empiric. Any agent selected for empirical therapy should have good activity against pathogens associated with CAP, a favorable tolerability profile and be administered in a simple dosage regimen for good compliance 4 . Strategies for the empirical treatment of CAP are complicated by shifting etiologies and the emergence of drug-resistant pathogens ${ }^{14}$. Streptococcus pneumonia has been identified as the commonest organism causing CAP all over the world 6,8,14-20. But some studies, over the last three decades, have reported of increased incidence of pneumonia due to "atypical" and gram- negative organisms $10,14,19,21-24$. Previously effective therapy for CAP has traditionally been accomplished with B- lactam antibiotics, macrolides, trimethoprim/ sulfamethoxazole and tetracyclins. However, increasing antibiotic resistance has been observed for several common pathogens in CAP including S. pneumonia, H. influenza, M. Catarrhalis, S.aurius and gram negative bacteria ${ }^{10}$. Increased prevalence of drug-resistant strains remains a primary 
concern in the treatment of $\mathrm{CAP}^{6}$. The respiratory fluoroquinolones have gained a reputation as a highly effective and well- tolerated option for the first-line treatment of CAP $\mathrm{C}^{6-8,25}$. Levofloxacin is a fluoroquinolone antibacterial agent with a broad spectrum of activity against Gram-positive and Gram-negative bacteria and atypical respiratory pathogens. It is active against both penicillin-susceptible and penicillin-resistant Streptococcus pneumonia and recommended for the empiric management of CAP in inpatients and outpatients $7,8,25-27$. Some studies showed that in the treatment of CAP Levofloxacin alone is comparable to or better than combination therapy like injectable $3^{\text {rd }}$ generation Cephalosporin plus Macrolides ${ }^{5}$. Levofloxacin was effective in treating patients infected with $S$. pneumonia that was nonsusceptible (intermediately resistant or resistant) to Penicillin 6 . Levofloxacin was also a beneficial treatment for CAP from a pharmacoeconomic perspective $7,8,28$. Several published articles provide data from clinical trials measuring the efficacy and safety of levofloxacin used in the treatment of CAP and CAPrelated infections ${ }^{6}$. So far we know there are limited data about efficacy of levofloxacin in the treatment of CAP in Bangladeshi population. The present study conducted to find out the effectiveness of Levofloxacin in CAP among Bangladeshi population.

\section{Materials and Methods}

This prospective observational study was conducted from February to November in 2010 at Uttara Adhunik Medical College Hospital. The study consists of four visits: first one for screening and enrollment, other 3 visits for assessment of safety and effectiveness. Second visit on day 2-4 during which patient on therapy, third visit 5-7 days after the last dose of the drug that is post therapy visit and fourth visit 28 days after the last dose of the drug that is post study follow-up. Approximately 6 weeks needed to complete the study. Total 50 patients aged more than 18 years, diagnosed pneumonia based upon clinical signs and symptoms of lower respiratory tract infection including at least 2 of fever, cough, greenish- yellow sputum, chest pain, shortness of breath, or evidence of decreased lung function during the physical examination, has a chest x-ray findings consistent with acute pneumonia, previously received antibiotics for pneumonia if the duration of therapy was $<24$ hours were included in the study. Patients having allergic or serious adverse reaction to any antibiotic similar to those used in this study or to penicillin, collection of pus in the cavity between the lung and the membrane that surrounds it, cystic fibrosis, severe kidney failure, decreased in white blood cell count, seizure disorder or any unstable psychiatric condition were excluded from this study. Those fulfilled the diagnostic criteria were enrolled in the study and treated with oral Levofloxacin $750 \mathrm{mg}$ once daily for 10 days or injectable Levofloxacin $500 \mathrm{mg}$ once daily for same duration. Data were collected by face to face interview with a predesigned questionnaire. Data were analysed with statistical software and presented in frequency and percentage in tabulated form.

\section{Results}

The mean \pm SD of age the respondents was $34.32 \pm 19.12$ with a range of 18-100. Among the respondents 31 $(62.0 \%)$ were male and $19(38.0 \%)$ were female. The male and female ratio was 1.63:1. Among the respondents $13(26.0 \%)$ were in the age group of less than 20 years, $15(30.0 \%)$ were in the age group of $21-30$ years, $5(10.0 \%)$ were in the age group of $31-40$ years, $7(14.0 \%)$ were in age group of $41-50$ years and rest $10(20.0 \%)$ were in the age group of more than 50 years. Among the respondents $3(6.0 \%)$ were diabetic and $10(20.0 \%)$ were hypertensive. Most of the respondents presented with fever (98.0\%) and cough $(100.0 \%)$ and chest pain was present in $66.0 \%$ cases. $48(96.0 \%)$ respondents presented with productive cough and rest $2(4.0 \%)$ respondents presented with productive with dry cough (table I).

Table- I: Distribution of characteristics of the respondents

\begin{tabular}{ccc}
\hline Variables & Frequency & Percentag \\
\hline Age group & & \\
20 & 13 & 26.0 \\
$21-30$ & 15 & 30.0 \\
$31-40$ & 05 & 10.0 \\
$41-50$ & 07 & 14.0 \\
$>50$ & 10 & 20.0
\end{tabular}

Mean \pm SD

$34.32 \pm$

$19.12(18-100)$

Sex

Male

31

Female

Male : Female

$1.63: 1$

Co morbid condition

DM

06.0

HTN

Clinical features

Fever

98.0

Chest pain

Cough

Dry 02

Productive 48

Mean \pm SD of total counts of WBC was $15.13 \pm 6.71$ per $\mathrm{cmm}$. Mean $\pm \mathrm{SD}$ of differential counts of neutrophils, lymphocytes eosinophils and monocytes were $78.00 \pm$ $10.46,15.50 \pm 8.53,2.50 \pm 1.60$ and $3.26 \pm 1.24$ respectively. Mean \pm SD of ESR was $58.58 \pm 29.97$ in first hour with a range of 9.00-125.00 in first hour (table II). 
Table- II: Distribution of the clinical Laboratory findings of the respondents $(n=50)$

\begin{tabular}{lrr}
\hline Laboratory findings & \multicolumn{1}{c}{ Mean \pm SD } & Range \\
\hline TC & $15.13 \pm 6.71$ & $4.10-31.70$ \\
Platelet count & $223.14 \pm 42.77$ & $100.00-320.00$ \\
ESR & $58.58 \pm 29.97$ & $9.00-125.00$ \\
Neutrophils & $78.00 \pm 10.46$ & $45.00-92.00$ \\
Lymphocytes & $15.50 \pm 8.53$ & $5.00-50.00$ \\
Eosinophils & $2.50 \pm 1.60$ & $1.00-9.00$ \\
Monocytes & $3.26 \pm 1.24$ & $1.00-600$ \\
\hline
\end{tabular}

Consolidation in left lower zone was the most common findings in left lower zone was the most common findings $(32.0 \%)$ followed by Consolidation in right mild zone $(30.0 \%)$. Other findings were consolidation in right lower zone, consolidation in left mild zone and consolidation in right upper zone were $20.0 \%, 08.0 \%$ and $6.0 \%$ respectively (table III).

Table- III: Distribution of the findings of the chest $\mathrm{X}$ ray of the respondents $(\mathrm{n}=50)$

\begin{tabular}{lcr}
\hline CliestXrayP/Avie & Frequency & Percent \\
\hline Consolidation in Rt & 15 & 30.0 \\
Mild zone & &
\end{tabular}

Consolidation in $\mathrm{Lt}$

16

lower zone

Consolidation in Rt

01

Penililas

Consolidation in Rt

Lower zone

Consolidation in Lt

Mild zone

Consolidation in $\mathrm{Rt}$

Upper zone

Consolidation in $\mathrm{Lt}$

Upper zone

Total 50

100.0

Among the respondents $16(32.0 \%)$ were treated with oral form and $34(68.0 \%)$ were treated with injectable form the levofloxacin (table IV).
Table- IV: Distribution of study population according to form of medicine taken $\quad(n=50)$

\begin{tabular}{lcc}
\hline Form of medicine taken & Frequency & Percent \\
\hline Oral & 16 & 32.0 \\
Injection & 34 & 68.0 \\
Total & 50 & 100.0 \\
\hline
\end{tabular}

Among the 50 respondents $46(92.0 \%)$ were improved with the treatment and rest $4(8.0 \%)$ were not improved with the treatment (table V).

Table- V: Distribution of the respondents according to the response of the treatment $(n=50)$

\begin{tabular}{lcc}
\hline Clinical features & Frequency & Percent \\
\hline Improved & 46 & 92.0 \\
Not- improved & 04 & 8.0 \\
Total & 50 & 100.0 \\
\hline
\end{tabular}

\section{Discussion}

In the present study the mean $\pm \mathrm{SD}$ of age of the respondents was $34.3 \pm 19.1$ years and $31(62.0 \%)$ were male and $19(38.0 \%)$ were female. The male and female ratio was 1.63:1. Advanced age has become a wellrecognized risk factor for death in patients with pneumonia. It may also be associated with reduced symptom reporting, raising the possibility that diagnosis and treatment may be delayed in older patients ${ }^{29}$. Marrie et al. (1996) in their study consisted of 149 Patients found a mean age $( \pm \mathrm{SD})$ of $41 \pm 15$ years and $36.0 \%$ of whom were men ${ }^{10}$. Kahn et al. (2004) retrospective reviewed 661 Levofloxacin-treated patients with pneumococcal CAP in 9 studies and found the mean age of patients was 53.4 years. Approximately one - third of patients were $>$ 65 years old in their study ${ }^{13}$. Patients with CAP often present with cough, fever, chills, fatigue, dyspnea, rigors, and pleuritic chest pain. Depending on the pathogen, a patient's cough may be persistent and dry, or it may be productive 20,30 . The sputum is usually yellowish or greenish in colour, Sometimes containing flecks of blood $^{20}$. In the present study most of the respondents presented with fever $(98.0 \%)$ and cough $(100.0 \%)$ and chest pain was present in $66.0 \%$ cases. Ninety six percent respondents presented with productive cough and rest only $4.0 \%$ respondents presented with dry cough. Metlay et al. (1997) in a study showed that respiratory and nonrespiratory symptoms are less commonly reported by older patients with pneumonia ${ }^{29}$. Mean \pm SD of total counts of WBC was $15.13 \pm 6.71$ per $\mathrm{cmm}$. Mean $\pm \mathrm{SD}$ of differential counts of neutrophils, lymphocytes eosinophils and monocytes were $78.00 \pm 10.46,15.50 \pm 8.53,2.50 \pm$ 1.60 and $3.26 \pm 1.24$ respectively. Mean \pm SD of ESR was $58.58 \pm 29.97$ in first hour with a range of 9.00-125.00. Melbye et al. (1992) in a study showed that those with radiological evidence of pneumonia had a higher mean 
white blood cell count (WBC) $)^{31}$. But a WBC of $>=10.4$ was not helpful in predicting radiologically defined pneumonia unless symptoms had been present for seven days or more. In CAP due to Streptococcus pneumonia, the commonest organism, leukocytosis is common and early in the disease, chest X-ray findings may be normal, but later, they may show classic lobar pneumonia ${ }^{20}$. Chest radiography (posteroanterior and lateral views) has been shown to be a critical component in diagnosing pneumonia. According to the latest American Thoracic Society (ATS) guidelines for the diagnosis and treatment of adults with CAP, " all patients with suspected CAP should have a chest radiograph to establish the diagnosis and indentify complications (Pleural effusion, multilobar disease)." Chest radiography may reveal a lobar consolidation, which is common in typical pneumonia; or it could show bilateral, more diffuse infiltrates commonly seen in atypical pneumonia. However, chest radiography performed early in the course of the disease could be negative ${ }^{30}$. In the present study cjonsolidation in left lower zone was the most common findings (32.0\%) followed by consolidation in right mild zone (30.0\%) Other findings were consolidation in right lower zone, consolidation in left mild zone and consolidation in right upper zone were $20.0 \%, 08.0 \%$ and $6.0 \%$ respectively. Broad-based, national surveillance studies have demonstrated that clinical isolates of S. pneumonia, $H$. influenza, and $M$. catarrhalis in the United states continue to be highly susceptible to levofloxacin ( $>99 \%$ of isolates) $)^{32-34}$. Many clinical trials support the effective and safe use of levofloxacin for the treatment of CAP and CAP- associated infection 6 . In the present study $32.0 \%$ were treated with oral form and $68.0 \%$ were treated with injectable form the levofloxacin. About 92.0\% were improved with the treatment. Kahn et al. (2004) in their retrospective review of 661 levofloxacin-treated patients showed that the overall clinical success rates for patients with CAP due to penicillin-resistant or macrolideresistant S. pneumonia were $94.7 \%$ (18 of 19) patients ) and $96.9 \%$ (31 of 32 patients), respectively ${ }^{13}$. Dunbar et al. (2003) in their study showed that the majority (99\%) of pathogens identified at study entry were fully susceptible to levofloxacin in vitro ${ }^{14}$.

Levofloxacin monotherapy is well tolerated, cost- effective treatment for patients with CAP. Further large scale multicentered study will help to strengthen this outcome.

\section{References}

1. Bradley JS, Byington CL, Shah SS, et al. The management of community-acquired pneumonia in children older than 3 months of age clinical practice guidelines by the Pediatric Infectious Diseases Society and the Infectious Diseases Society of America. Clin Infect Dis. 2011;53:25.

2. Harris M, Clark J, Coote N, et al. British Thoracic society guidelines for the management of communityacquired pneumonia in children: update 2011.Thorax 2011 Oct;66(Suppl 2):1-23
3. Haessler S and Schimmel JJ. Managing communityacquired pneumonia during flu season. Cleveland Clinic Journal of Medicine. 2012;79(1):67-78.

4. Perry CM and Goa KL. Community-Acquired Pneumonia and its Management: the Role of Levofloxacin. Disease Management \& Health Outcomes. 2001;9(1):43-64.

5. Konstantinos Z. Vardakas, Ilias I. Siempos, Alexandros Grammatikos, Zoe Athanassa, Ioanna P. Korbila, and Matthew E. Falagas. DSc Respiratory fluoroquinolones for the treatment of community acquired pneumonia: a meta- analysis of randomized controlled trials. CMAJ. 2008;179(12):1269-1277.

6. Thomas MF Jr. Current Challenges in the Treatment of Community- acquired Pneumonia. Clin Infect Dis. 2004 38 (Supplement 1);SI-S4. Doi: 10.1086/378404

7. Wasserfallen J-B, Erard V, Cometta A, Calandra T, Lamy O. Cost- effectiveness of full- course oral levofloxacin in severe community -acquired pneumonia. Eur Respir J. 2004;24:644-648.

8. Garibaldi RA. Epidemiology of community acquired respiratory tract infections in adults: Incidence, etiology and impact. Am J Med. 1985;78:325-75.

9. Fang GD, Fine M, Orloff $J$, et al. New and emerging etiologies for community - acquired pneumonia with multicenter study of 359 cases. Medicine (Baltimore ). 1990;69:307-16.

10. Marrie TJ, Durrant H, Yastes L. Community acquired pneumonia requiring hospitalization: A five year prospective study. Rev Infect Dis. 1989;11:586-99.

11. Toores A, Serra- Batlles J, Ferrer A, Jimenez P, Cellis $\mathrm{R}$, Cobo E, at al. Severe community acquired pneumonia; epidemiology and prognostic factors. Am Rev Respir Dis. 1991;1144(2):312-8.

12. Panchon J, Pardos Capote F, Cuella JA, Garnacho J, Veerano A. Severe community acquired pneumonia: Etiology, prognosis and treatment. Am Rev Respir Dis. 1990;142:369-73.

13. Kahn JB, Bahal N, Wiesinger BA, Xiang J. Cumulative Clinical Trial Experience with Levofloxacin for Patients with Community- Acquired PneumoniaAssociated Pneumococcal Infectious Diseases. 2004;38 (Suppl 1):S34-42.

14. Dunbar LM, Wunderink RG, Habib MP, Smith LG, Tennenberg AM, Khashab MM at al. High- Dose, ShortCourse Levofloxacin for Community- acquired Pneumonia: A New Treatment Paradig. Clin Infect Dis. 2003;37(6):752-760.

15. Howard LS, Sillis M, Pasteur MC, Kamath AV, Harrison BD. Microbiological profile of community acquired pneumonia in adults over the last 20 years. $\mathbf{J}$ Infect. 2005;50:107-113. 
16. A1- Ghizawi GJ, A1- Sulami AA, Al- Taher SS. Profile of community- and hospital- acquired pneumonia cases admitted to Basra General Hospital, Iraq. East Mediterr Health J. 2007;13:230-42.

17. Capoor MR, Nair D, Aggarwal P, Gupta B. Rapid diagnosis of community acquired pneumonia using the Bac T/ alert 3 D system. Braz J Infect Dis. 2006;10:352-6.

18. Lee KH, Hui KP, Tan WC, Lim TK. Severe Community-Acquired Pneumonia in Singapore. Singapore Med J. 1996;37:374-7.

19. Chawla K, Mukhopadhay C, Majumder M, Bairy I. Bacteriological profile and their antibiogram from cases of acute exacerbations of chronic obstructive pulmonary disease: A hospital based study. J Clin Diagn Res. 2008;2:612-6.

20. Prasad R. Community Acquired Pneumonia: Clinical Manifestations. JAPI. 2012;60: 10-12.

21. Ailani RK, Agastya G, Ailani R, Mukunda BN, Shekhar R. Doxycycline is a cost effective therapy for hospitalized patients with community acquired pneumonias. Arch Intern Med. 1999;159:266-70.

22. Almirall J, Morato I, Riera F, Verdaguer A, Priu R, Coll $\mathrm{P}$, et al. Incidence of community acquired pneumonia and Chlamydia pneumonia infection. A prospective multi centre study. Eur Respir J. 1993;6:14-8.

23. Amsden GW. Pneumococcal macrolide resistance: Myth or reality? J Antimicorb Chemother 1999;44(1):1-6.

24. Berntsson e, Lagergard T, Strannegard O, Trollfors B. Etiology of community acquired pneumonia in out patients. Eur J Clin Microbiol. 1986;5:446-7.

25. Croom KF and Goa KL. Levofloxacin: A review of its use in the treatment of bacterial infections in the United States. Druge. 2003;63(24):2769-802.

26. Mathis AS and Schiller DS. Pharmackokinetic and Pharmacodynamic interactions with Levofloxacin in Renal transplant Patients with Suspected Pneumonia. The Open treansplantation Journal. 2008;2:35-39.
27. Mandell LA, wunderink RG, Anzueto A, et al. Infectious diseases society of American thoracic society consensus guidelines on the management of communityacquired pneumonia in adults. Clin Infect Dis. 2007;44(Supp12):S27-72.

28. Palmer CS, Zhan C, Elixhauser A, Halpern MT, Ranee L, Feagan BG et al. Economic assessment of the community- acquired pneumonia intervention trial employing levofloxacin. Clinical Terapeutics. 2000;22(2):250-264.

29. Metlay JP, Schulz R, Li YH, Singer DE, Marrie TJ, Coley CM. et al. Influence of age on symptoms at presentation in patients with community- acquired pneumonia. Arch Intern Med. 1997;157(13):1453-9.

30. Lutfiyya MN, Henley E, Chang LF, Reyburn SW. Diagnosis and Treatment of Community- Acquired Pneumonia. Am Fam Physiscian. 2006 Feb 1;73(3):442450 .

31. Melbye H, Straume B, Brox J. Laboratory tests for pneumonia in general practice: the diagnostic values depend on the duration of illness. Scand J Prim Health Care. 1992;10:234-40.

32. Gotfried MH. Epidemiology of clinically diagnosed communityacquied pneumonia in the primary care setting: results from the 1999-2000 Respiratory Surveillance Program. Am J Med. 2001;111(Suppl 9A):25S-29S.

33. Pfaller MA, Ehrhardt AF, Jones RN. Frequency of Pathogen occurrence and antimicrobial susceptibility among community- acquired respiratory tract infections in the Respiratory Surveillance Program: microbiology from the medical office practice environment. Am J Med. 2001; 111(Supp19A):4S-12S.

34. Thornsberry C, Sahm DF, Kelly LJ. Regional trends in antimicrobial resistance among clinical isolates of Streptococcus pneumonia, Haemophilus influenza, and Moraxella catarrhalis in the United States: results from the TRUST surveillance program, 1999-2000.Clin Infect Dis. 2002;34(Suppl 1):4-16. 